\title{
Diosas en la literatura fantástica: "El ídolo" de Emiliano González
}

\author{
CRistina Mondragón ${ }^{*}$
}

Resumen:

El artículo explora el tema de la reelaboración literaria de figuras míticas antiguas, cuando ya han sido desacralizadas y sus religiones han desaparecido. Para analizar este fenómeno de resemantización, se apoya en el ejemplo de un relato fantástico de Emiliano González titulado "El ídolo" (1989). La pregunta es si la representación literaria actual que se hace de antiguas figuras sagradas no es una forma de proyectar en los mitos de otras culturas los miedos y filias que provoca el 0 tro representado, lo prohibido por el orden de la cultura actual, incluso lo que está más allá del poder humano. En el caso particular del relato analizado, la respuesta literaria muestra un temor hacia el regreso de ciertas divinidades del pasado, en especial ciertas diosas paganas de la fertilidad y el placer sexual; se teme que el orden oficial no haya destruido todo lo que representan.

Palabras clave:

E miliano G onzález, relato fantástico, narrativa mexicana reciente, Mito, Mircea Eliade, representaciones literarias de mitos del pasado, miedo al Otro, tabú.

Uno de los procesos más interesantes que aborda la Historia de las Ideas es, sin duda, aquél que siguen los relatos míticos desde su narración como textos sagrados hasta su escritura como textos

*Facultad de Filosofía y Letras, Universidad Autónoma de México. 
literarios. Los lugares, los motivos, los personajes que una vez fueron representación de lo sobrenatural sagrado se transforman, y se recuperan, en algún otro momento histórico, en textos literarios con nuevas características, pero sin perder del todo la esencia divina que tuvieron en el principio. D espués de todo, el mito vivo contiene rasgos que dejan una impronta permanente en el imaginario colectivo. En efecto, el discurso mítico, mientras se encuentra en el contexto que le permite cumplir las funciones para las que fue generado, presenta peculiaridades que difícilmente encontramos en otro modo discursivo: el carácter hierofánico, su valoración como relato verdadero y fehaciente, y el poder mágico que contagia al chamán o sacerdote que lo narra en el ritual -recordemos que el mito, en tanto que símbolo desplegado, reconstruye el tiempo de los orígenes, es decir, abre un espacio temporal sagrado que comunica a los oyentes del relato mítico con el illud tempus, el tiempo sagrado de los comienzos. De ahí que "conocer los mitos es aprender el secreto del origen de las cosas" (Eliade, Mito y realidad 21), y se convierte en un saber oculto, esotérico, ya que su conocimiento va acompañado de un poder mágico-religioso (Eliade 21-22). Sus personajes, de naturaleza sobrenatural, se consideran verdaderos: tanto dioses como héroes existieron en el tiempo de los comienzos, y recuperan existencia mediante el poder actualizador del mito. ¿Q ué pasa, pues, con ellos cuando, desacralizadas sus historias e incluso muertas las religiones que les dieron vida, aparecen como motivos centrales en el discurso literario? ¿Pierden acaso las características sagradas que les brindaban existencia en la antigüedad? Más aún, si una de las formas de reconocer al O tro es a partir de su representación, ¿no será que la representación que hacemos de sus dioses muestra nuestras filias o fobias hacia el Otro representado?

Es por esto que resulta tan revelador el hecho de encontrarnos con textos literarios que recuperan, ya secularizadas, una serie de figuras míticas que, fatalmente, conservan algo de su antigua naturaleza sagrada; incluso, un dios, al convertirse en motivo literario, puede adquirir características que antes no formaban parte de su naturaleza, puede transformarse y asumir características de otro u otros dioses, o bien puede potenciar las facultades que le eran natu- 
rales. La impronta de su naturaleza simbólica permanece aún salvando distancias espacio-temporales importantes, inclusive cuando el símbolo, extrañado de sí mismo, puede ya no compartir con su mito de origen nada más que el nombre, y tal vez algún rasgo esencial conservado en la memoria colectiva.

Ahora bien, volviendo a su presencia literaria, a pesar de los cambios que pueda presentar un determinado símbolo, o tal vez precisamente por estos cambios, aquello simbolizado adquiere la fuerza suficiente para convertirse, más allá del mito, en motivo usual de la literatura en otros modos de discurso: la presencia de los dioses antiguos en textos modernos es un asunto que se ha estudiado ya con atención, baste que recordemos el término que recupera Louis Vax para referirse a ellos en su tipología de motivos fantásticos, en la que los llama "La horda de los dioses muertos", dioses que vuelven del pasado con todo su poder para amenazar un nuevo orden de mundo (Vax 34). Precisamente de esta Horda, en el presente trabajo, hablaré de la presencia de dos diosas de la fecundidad, Venus y Astarté, a partir de un breve relato del escritor E miliano González, "El ídolo".

Este relato aparece en Casa de horror y de magia (1989). El volumen inicia con la noveleta "El discípulo: una novela de horror sobrenatural", que amén de recordar en su estilo y estructura algunos de los relatos fantásticos de Arthur Machen (especialmente "El pueblo blanco"), hace en su primera parte un recuento de algunos de los relatos que conforman el resto del libro. En efecto, en "El discípulo..." un narrador en primera persona se encuentra un texto de otro autor, un personaje llamado Aurelio Summers, cuyo relato, "La maldición", narra

la historia de una virgen fabricada a base de un extraño metal negro, que transformaba a las pobres damas estériles que le pedían milagros en fértiles engendradoras de monstruos: una historia macabra, con imaginería decadentista, muy certera con su humor negro y, por supuesto, desconocida en español... (González 9-10) 
Resulta que, tras algunas indagaciones, este narrador en primera persona encuentra el relato en una colección mayor, único libro publicado del supuesto autor, El sátiro, cuya edición tuvo escasos cien ejemplares; nos da luego una breve descripción de los siete restantes relatos contenidos en el volumen, aparte de "La maldición", de los cuales otros dos, en forma especular, presentan el mismo argumento de dos relatos de horror que conforman Casa de horror y de magia. La novela sigue por su muy decadentista y decimonónico camino, revelando que G onzález es un asiduo lector de Machen, Lovecraft, Poe y seguramente de Maupassant y Merimée.

A hora bien, en efecto, el argumento que Emiliano G onzález pone en el relato de su personaje Aurelio Summers aparece como narración independiente en "El ídolo", cuyo título se completa con el subtítulo "extracto de las Memorias de una dama estéril" y que pertenece a la segunda parte del volumen, "Cuentos de horror, de nostalgia y de anticipación" (la tercera parte estará comprendida por dos cuentos eróticos: "Memorias de un caracol" y "El jardín del placer"). En el relato que nos ocupa, "El ídolo", una narradora en primera persona cuenta su encuentro con esta figura, la virgen fundida en el "extraño metal negro", a la que describe: "aquella virgen era como un sol negro" (67), y luego explica su origen, "según el párroco, habían fundido en la Edad Media una estatua fenicia de Astarté y con el mismo extraño metal negro habían fabricado a la Virgen" (67). Según el argumento de "La maldición", el relato del personaje Aurelio Summers en "El discípulo..." , esta figura brinda fecundidad a las infértiles, pero sólo para generar monstruos; entonces en "El ídolo", dado que nos encontramos frente a un narrador homodiegético, en una narración supuestamente en forma de memorias "de una dama estéril", se focaliza la información narrativa en una candidata para "engendradora de monstruos".

El hecho de que la estatua fundida fuera primero de Astarté resulta significativo, pues, como dice el texto, "la virgen representaba el Santo Dolor, pero antes había representado la Fertilidad, y todos sabemos que el sacrilegio - en este caso, la fundición del extraño metal negro- permite la metamorfosis de diosa en demonio: la Fertilidad se convierte en Lujuria" (67). Según el texto, la diosa 
sufre una metamorfosis al ser fundida su estatua, sin embargo, su poder permanece y su aspecto numinoso ${ }^{1}$ se manifiesta al menos en la imposibilidad de mirarla mucho tiempo. Su belleza, continúa, es ambigua, causa más dolor que placer, y se concentra en sus ojos: "no podría recordar los rasgos de su cara, ahora que escribo esto: sólo recuerdo sus ojos -dos ardientes y glaucos berilos- y el efecto general que me produjo" (67). Ahora bien, según Mircea Eliade, las diosas de la fecundidad comparten ciertas características, "todas las experiencias religiosas en relación con la fecundidad y el nacimiento tienen una estructura cósmica. La sacralidad de la mujer depende de la santidad de la Tierra. La fecundidad femenina tiene un modelo cósmico: el de la Terra mater, la $\mathrm{G}$ enetrix universal" (Eliade, L 0 sagrado y lo profano 107), y la estatua que ahora representa una forma distinta de "diosa", una Mater dolorosa, tiene en su esencia parte de la diosa fenicia de la fecundidad, de ahí que el aspecto numinoso se manifieste como algo amenazante. Por otra parte, no podemos olvidar que la Astarté original, fenicia (quien también recibía el nombre de Astarot, A shtar, y entre los acadios, Ishtar) fue una diosa con un culto muy extendido: "as A starte she was work shipped as far west as Carthage, Sidily, Sardinia and Cyprus" (Wyche) y sus estatuas se colocaban en los altares domésticos a fin de atraer buenas cosechas, protección y tranquilidad en el hogar. Conformaba, junto con su hermano-consorte Baal y con El, protector y creador del universo, una triada en que ella asumía el papel de Diosa madre. No obstante lo anterior, es evidente que el aspecto ominoso de la Astarté del relato parece tener poca relación con la Astarté doméstica fenicia; sin embargo, recordemos que se le equipara también a la Ishtar acádica y esta diosa, según Mircea Eliade, "durante su apogeo, Innana-Ishtar era diosa, a la vez, del amor y de la guerra, es decir, que regía la vida y la muerte; para expresar la plenitud de sus poderes se la llamaba hermafrodita (Ishtar barbata)" (Eliade, H istoria de las creencias y las ideas religiosas 98).

${ }^{1}$ Para los fines de este trabajo, me ciño a la definición de Rudolf Otto, quien propuso el término para designar una cierta característica de lo sagrado entendida como el mysterium tremendum. 
Evidentemente estamos frente a una diosa que, en principio, pertenece a los rangos más altos del panteón fenicio, que más adelante se equipara a Ishtar, y ésta a su vez con Innana, todas diosas del cercano oriente, cuyo culto fue de los más importantes y, luego de la síntesis sumero-acádica, más extendidos en oriente e incluso, como hemos visto, en las islas del Mediterráneo. Ahora bien, como diosa de fertilidad, su culto implicaba una sexualidad ritual que, con el advenimiento del cristianismo, se convirtió en pecaminosa, y por lo tanto había que desaparecerla. Pero una diosa con tan grandes poderes no puede desaparecer fácilmente del imaginario, de manera que el cristianismo y el tiempo la convirtieron en demonio. El proceso de cómo una diosa se transforma en demonio es largo y sería materia de otro trabajo, así que retomaré lo que propone el demonólogo Jean Wier, ya en el siglo dieciséis, la organización infernal y demoniaca. Según Wier, cada mes del calendario cristiano está asociado a un demonio distinto, y abril aparece asociado a Astarté. Por otra parte, recordemos también que, una vez que Lucifer y su cohorte de seguidores fueron arrojados al Averno, se organizaron en una Corte Infernal que parodia la Corte Celestial, y ahí encontramos la presencia de Astarot entre los Duques del Infierno, entre cuyas funciones se encuentran, "procure l'amitié des grands seigneurs et est, aux enfers, le trésorier. Il connait le passé et l'avenir, enseigne les arts libéraux et commande quarante legions. Il faut l'évoquer le mercredi [...]. Il connait toute l'histoire de la Création, les fautes et les chutes des anges. Astarté est la femelle d'Astaroth" (Mozzani). La descripción, para este momento, ya es completamente distinta: de diosa de la fecundidad y protectora del hogar, Astarté, no sólo se desdobló en varón y hembra, sino que se convirtió en mujer del ahora demonio Astarot. La representación que "El ídolo" hace de la diosa corresponde de manera muy cercana a la metamorfosis que sufrió después del cristianismo.

Podríamos suponer ahora que la transformación de la manifestación numinosa en ominosa, tal y como aparece en el relato de Emiliano G onzález, puede deberse a tres factores: en primer lugar, al poder primordial de la diosa que conserva desde la antigüedad como $\mathrm{G}$ enetrix, ya que la fecundidad y sus ritos también se revisten 
del carácter mágico que caracteriza al relato mítico; en segundo lugar, al sincretismo que la religión cristiana hizo de muchos de los dioses del oriente con los demonios que necesitaba para poblar un nuevo espacio mítico como el infierno, de manera que Astarté se transforma directamente, incluso conservando su nombre antiguo, en demonio; y tercero, que habiéndose convertido ya en representación demoniaca en el imaginario cultural cristiano, aparezca convertida en Virgen del Santo D olor. Es la unión de los contrastes lo que brinda una gran fuerza a este brevísimo relato: la fecundidad y la virginidad, la maldad y la bondad absolutas, la belleza de lo sagrado y la repulsión ante lo impuro se mezclan en una sola representación escultórica.

En efecto, la fuerza que emana de esta figura se representa textualmente en el breve diálogo entre el párroco y la narradora: " - ¿Y cómo es que la tienen aquí, en este lugar de salvaciones? -pregunté después de un momento-. Porque es la única prueba de lo sagrado que existe. Q uienes entran aquí, no vuelven a ser ateos" (68). Vemos aquí que el aspecto hierofánico de la diosa no se niega, sino que el autor une lo numinoso con lo ominoso en una sola cosa: ver esta imagen equivale a ser creyente, pero, ¿de qué? “¿Qué tipo de milagros concedería ese monstruo?" se pregunta la narradora, para afirmar más adelante: "no lograron hacerme creer en el cielo... pero sí en el infierno y sobre todo en Astaroth. Porque si Astarté vuelve fértiles a las estériles, Astaroth propicia los partos monstruosos" (68).

Hasta este momento del relato, la sola unión de Astarté con la virgen del Santo D olor ha funcionado para crear una isotopía tonal de amenaza sobrehumana: la irrupción de lo sagrado se manifiesta de una forma bizarra que presagia acontecimientos funestos para la narradora, pero aún no sucede realmente nada, salvo las percepciones extrañas y las pesadillas que ésta tiene por la noche luego de su enfrentamiento con la estatua, "tan imprecisas como la horrible muñeca... aunque conservo la vaga sospecha de que el sexo y la sangre jugaban un papel esencial en ellas" (68). Continúa el relato de las memorias y aparece otra alusión importante: "fuera de la luna y de Venus, no había más luminarias en el cielo cuando tuve las pesadillas. D e modo que me mantengo alejada del amor siempre 
que los dos astros dominan la bóveda nocturna" (68-69). Otra vez nos encontramos con una diosa de la fecundidad, en este caso Venus. No deja de chocar un poco que la alusión a la diosa griega sea por medio de la estrella que lleva su nombre; sin embargo, no se puede pasar por alto la mezcla entre los elementos que aparecen en las pesadillas y la presencia venusiana: sexo y sangre. A sí pues, luego de visitar una diosa propiciatoria de fecundidad oculta en una representación del Dolor, aparece en el cielo Venus, o Afrodita la que, según Eliade, "pone el deseo lo mismo en las fieras que en los hombres y los dioses" (Eliade, Mito y realidad 363). Así, con la sola mención de Venus Afrodita se abre la posibilidad de lo fantástico cuando la narradora culmina el relato: "me obsesiona un temor: acaso formulé, inconscientemente, una plegaria, y esa Cosa me escuchó... porque - sí, es necesario decir esto- lo que vi al cerrar los ojos, aquel omnipotente sol parecía escudriñar, sondear en mi alma hasta los resquicios más profundos, hasta los deseos más secretos..." (69). El deseo, potencia de Afrodita, que puede llevar a la fecundidad, con lo cual se cumpliría la "maldición" del título en el relato de Aurelio Summers: la fecundidad generadora de monstruos, mientras que el ídolo del relato independiente, en tanto que representa una "diosa madre" que procreó sin intervención de varón, la Virgen María, posibilita la fecundidad sin nada más que deseo. Por otra parte, Afrodita también representa "una justificación religiosa de la sexualidad, pues al ser provocados por Afrodita, hasta los excesos y las violencias sexuales habrán de reconocerse como de origen divino" (Wyche). D e cualquier manera, la narradora ha quedado en posesión de la diosa: ya sea de la D olorosa, de Astarté o de Venus Afrodita, parece, por los puntos suspensivos al final del relato, que las potencias de las tres confluyen e irrumpen en su vida para cambiarla por completo.

Ahora bien, al mencionar a Venus en este contexto no podemos dejar de reconocer el relato fantástico clásico al que remite invariablemente el motivo de la diosa fundida que conserva su poder destructor, "La Venus d'Ille" de Merimée. En efecto, una de las partes medulares del relato, la descripción de la estatua, establece importantes semejanzas entre ambas figuras. La deixis de referencia, y 
por tanto el punto focal, también están fijas en un narrador homodiegético. La isotopía descriptiva y tonal se establecen en torno a la sensualidad y la belleza de la estatua, pero cambia en un momento dado hacia una tonalidad disfórica respecto de lo que proyecta: "dédain, ironie, cruauté, se lisaient sur ce visage d'une incroyable beauté cepedant" (Mérimée 418). En el caso de la Venus de Mérimée, también los ojos tienen una función importante para la descripción tonal de la diosa: "Elle vous fixe avec ses grands yeux blancs... On dirait qu'elle vous dévisage. On baisse les yeux, oui, en la regardant" (411). En ambas estatuas los ojos manifiestan el poder sagrado, ya sea por su belleza, ya sea por su aspecto amenazante. En el cuento de Mérimée, el descubrimiento de la Venus de bronce trae funestas consecuencias tanto a la familia de $\mathrm{M}$. de Peyrehorade como para el pueblo donde se desentierra, pues finalmente Venus representa el paganismo y la fecundidad, los poderes que regresan del pasado para amenazar el nuevo orden del mundo. Al final del cuento la estatua de Venus sufre el mismo destino que la de Astarté: la funden y con ella hacen una gran campana para la iglesia del pueblo; y al parecer la campana mantiene también sus poderes, pues cada vez que la tocan sucede alguna desgracia.

No es difícil que Emiliano G onzález haya conocido este cuento, ya que es uno de los cuentos paradigmáticos del género fantástico clásico. Y el motivo en ambos es el mismo: el regreso de una fuerte diosa de fertilidad al mundo cristiano, cuya presencia, oculta bajo una nueva forma, domesticada bajo el influjo de una nueva religión oficial, sigue amenazando el orden natural.

Así pues, Emiliano G onzález recupera este motivo y lo reelabora de manera que una serie de símbolos confluyan en una sola estatua. La acción, situada en algún pueblito perdido en Alemania, muestra cómo, a pesar del tiempo y el espacio, el poder de estas diosas sigue generando la sensación de impotencia ante lo sagrado. Mediante la combinación de los símbolos indicados, "El ídolo", y por efecto de espejo "La maldición" de Summers, nos muestran que, en algún lugar del imaginario colectivo, permanecen ocultos los temores ante la majestad de las diosas de la vida y la muerte. Tal vez las ocultemos detrás de imágenes más cercanas y conocidas, tal vez encon- 
trarlas en un relato de ficción resulte más tranquilizador que mirarlas de frente: su belleza, diría el párroco de la iglesia de "El ídolo", es más soportable si se mira reflejada en el espejo. En este caso, el espejo es doble, y aun así, nos sigue causando horror, ¿será que le tememos a las pesadillas, o será que tememos encontrarnos con nuestros deseos más secretos...?

\section{Bibliografía}

Eliade, Mircea. H istoria de las creencias y las ideas religiosas. V ol. I. D e la E dad de piedra a los misterios de E leusis. Paidós O rientalia 63. Tr. Jesús Valiente Malla. Barcelona: Paidós Ibérica, 1999.

. Lo sagrado y lo profano. Paidós O rientalia 57. Tr. Luis Gil Fernández y Ramón Alfonso Díez Aragón. Barcelona: Paidós Ibérica, 1998.

. Mito y realidad. Tr. Luis Gil. Barcelona: Kairós, 1999.

González, Emiliano. Casa de horror y de magia. México: Joaquín Mortiz, 1989.

Mérimée, Prosper. Romans et nouvelles. Bibliothèque de la Pléiade 21. París: Gallimard, 1951.

Mozzani, Éloïse. "D emons." L e livre des superstitions. M ythes, croyanoes et leyends. París: Robert Laffont, 1995.

Otto, Rudolf. L o santo. L o racional y lo irracional en la idea de D ios. Tr.

Fernando Vela, El libro de bolsillo-Humanidades 4106. Madrid:

Alianza Editorial, 2001.

Vax, Louis. A rtey literatura fantásticas. Tr. Juan Merino, 2a. ed. Buenos

Aires: Editorial Universitaria de Buenos Aires, 1971.

Wyche, Peter. "Astarte". E ncyclopedia Mythica, 1 de 0 ctubre, 2005, <http:/ / www.pantheon.org/ articles/ a/ astarte.html> 